\title{
2H-SiC Films Grown by Laser Chemical Vapor Deposition
}

\author{
Akihiko Ito*, Hitoshi Kanno, Takashi Goto \\ Institute for Materials Research, Tohoku University, 2-1-1 Katahira, Aoba-ku, Sendai 980-8577, Japan \\ *Corresponding author: E-mail: itonium@imr.tohoku.ac.jp; \\ Tel: +81-22-215-2106; Fax: +81-22-215-2107
}

\begin{abstract}
We demonstrated the synthesis of $2 \mathrm{H}-\mathrm{SiC}$ films on graphite and (0001) sapphire
substrates by laser chemical vapor deposition. A tris(dimethylamino)silane was used as a novel precursor for the synthesis of $\mathrm{SiC}$ films in a $\mathrm{CH}_{4}$ atmosphere. The $2 \mathrm{H}-\mathrm{SiC}$ films were obtained at a deposition temperature of $920 \mathrm{~K}$ on the sapphire substrate. The films comprised $a$-axis-oriented columnar grains and their in-plane orientation relationship was [1000] 2H-SiC // [0001] sapphire and [0001] 2H-SiC // [1000] sapphire. The films were deposited at the rate of $182 \mu \mathrm{m} \mathrm{h}^{-1}$.
\end{abstract}

Keywords: Silicon Carbide; 2H-SiC; Film; Chemical Vapor Deposition 


\section{Introduction}

Silicon carbide $(\mathrm{SiC})$ is widely used in high-temperature structural materials, protective coatings, and semiconductor devices [1]. SiC has more than 200 polytypes, including zinc blend-type cubic (3C) and many hexagonal structures such as $2 \mathrm{H}, 4 \mathrm{H}, 6 \mathrm{H}$, and $15 \mathrm{R}$ because of a wide variety of stacking sequence of the $\mathrm{Si}-\mathrm{C}$ bilayer. Plates of $3 \mathrm{C}-\mathrm{SiC}$ and $4 \mathrm{H} / 6 \mathrm{H}$ single crystalline wafers are commercially produced by chemical vapor deposition (CVD) and sublimation, respectively. However, 2H-SiC films to the best of our knowledge have never been prepared by CVD.

The band gap of $2 \mathrm{H}-\mathrm{SiC}$ is wide $(3.33 \mathrm{eV})$, as indicated by the absorption and luminescence measurements of $2 \mathrm{H}-\mathrm{SiC}$ whiskers [2]. This value is larger than that exhibited by $3 \mathrm{C}-\mathrm{SiC}(2.2 \mathrm{eV})$, 4H-SiC (3.26 eV), and 6H-SiC (3.00 eV) [3]. In addition, Monte Carlo simulations predict a higher electron mobility for $2 \mathrm{H}-\mathrm{SiC}\left(1200 \mathrm{~cm}^{2} \mathrm{~V}^{-1} \mathrm{~s}^{-1}\right)$ than $3 \mathrm{C}-\mathrm{SiC}\left(900 \mathrm{~cm}^{2} \mathrm{~V}^{-1} \mathrm{~s}^{-1}\right), 6 \mathrm{H}-\mathrm{SiC}\left(370 \mathrm{~cm}^{2} \mathrm{~V}^{-1}\right.$ $\left.\mathrm{s}^{-1}\right)$, and $4 \mathrm{H}-\mathrm{SiC}\left(720 \mathrm{~cm}^{2} \mathrm{~V}^{-1} \mathrm{~s}^{-1}\right)[3,4] .2 \mathrm{H}-\mathrm{SiC}$ is a promising semiconductor material compatible with wurtzite-type group-III semiconductors, such as AlN, GaN, and $\mathrm{ZnO}$.

Only whiskers of $2 \mathrm{H}-\mathrm{SiC}$ have been obtained by CVD with the pyrolytic decomposition of Si chloride precursors, such as $\mathrm{CH}_{3} \mathrm{SiCl}_{3}$ or $\mathrm{SiCl}_{4}$ with $\mathrm{C}_{6} \mathrm{H}_{5} \mathrm{CH}_{3}$ or $\mathrm{CCl}_{4}$ in a $\mathrm{H}_{2}$ atmosphere at $1573-1773 \mathrm{~K}$ [5-9]. Films of 3C-SiC are mostly obtained by CVD at a wide range of deposition temperatures (1373-2673 K), except for epitaxial growth of $4 \mathrm{H}$ - and $6 \mathrm{H}-\mathrm{SiC}$ films on single-crystal substrates [1,10,11]. Although $2 \mathrm{H}-\mathrm{SiC}$ may be stable at less than $1673 \mathrm{~K}$ [12], 2H-SiC films have never been 
synthesized by CVD. Since CVD is a versatile technique to form a conformal coating in a wide area, a

novel CVD technique to produce $2 \mathrm{H}-\mathrm{SiC}$ films should be developed.

Crystalline SiC films can be prepared at a lower deposition temperature by metalorganic precursors than by halide precursors [1]. Although the use of low deposition temperatures often resulted in an amorphous film or absence of deposition [1,13], we have reported that laser irradiation during CVD enables the formation of $3 \mathrm{C}$-SiC films at lower temperatures using an alkylsilane precursor $\left(\mathrm{Si}_{2}\left(\mathrm{CH}_{3}\right)_{6}\right)$ $[14,15]$. An aminosilane precursor has been used for preparing $\mathrm{SiO}_{2}$ thin films [16] and amorphous silicon carbonitride films [17]; however, it has never been used for the growth of crystalline CVD-SiC films.

In this study, we demonstrate the preparation of $2 \mathrm{H}-\mathrm{SiC}$ films on graphite and (0001) sapphire substrates by laser CVD using an aminosilane precursor in a $\mathrm{CH}_{4}$ atmosphere. The effect of deposition conditions on the orientation and microstructure of the $2 \mathrm{H}-\mathrm{SiC}$ films were investigated.

\section{Experimental procedure}

The CVD apparatus used in this study has been described elsewhere [18]. Tris(dimethylamino)silane (3DMAS, $\left.\mathrm{SiH}\left(\mathrm{N}\left(\mathrm{CH}_{3}\right)_{2}\right)_{3}\right) \quad$ (Kojundo Chemical, Sakado, Japan) was evaporated at $273 \mathrm{~K}$ and the vapors were transported to the deposition chamber using Ar as the carrier gas.

$\mathrm{CH}_{4}$ was introduced into the chamber separately through a double-tube nozzle. The total pressure of the chamber was maintained at $800 \mathrm{~Pa}$. A graphite disc $(10 \mathrm{~mm}$ in diameter and $1 \mathrm{~mm}$ in thickness $)$ and 
(0001) sapphire plate $(10 \mathrm{~mm}$ in size and $1 \mathrm{~mm}$ in thickness) were used as substrates. The entire substrate

was irradiated with a continuous-wave Nd:YAG laser $(\lambda=1064 \mathrm{~nm})$. The deposition temperature $\left(T_{\mathrm{dep}}\right)$

was measured using a thermocouple. The deposition rate was calculated using the film thickness and

deposition time $(0.6 \mathrm{ks})$.

The phase compositions were determined by X-ray diffraction (XRD) (Ultima-IV; Rigaku,

Tokyo, Japan) using $\mathrm{Cu} \mathrm{K} \alpha$ radiation and a silicon strip detector in the range of $2 \theta=20^{\circ}-80^{\circ}$ at the scan speed of $40^{\circ} \mathrm{min}^{-1}$. A slow scan was performed with a scintillation counter and a graphite monochromator in the range of $2 \theta=40^{\circ}-55^{\circ}$ at the scan speed of $0.1^{\circ} \mathrm{min}^{-1}$. The microstructures were observed with a scanning electron microscope (SEM) (S-3100H; Hitachi, Tokyo, Japan) and a transmission electron microscope (TEM) (EM-002B; Topcon, Tokyo, Japan). The intensity profile by azimuthal integration of selected-area electron diffraction (SAED) pattern was drawn using the Diffraction Ring Profiler software [19]. The schematic of the film crystal structure was created using the VESTA software [20]. The binding energies of the $\mathrm{C}, \mathrm{Si}$, and $\mathrm{N}$ atoms were measured with X-ray photoelectron spectroscopy (XPS), which was performed using $\mathrm{Al} \mathrm{K} \alpha$ radiation (Shimadzu-Kratos AXIS-ULTRA DLD). $\mathrm{Ar}^{+}$ion bombardment was conducted for $1.8 \mathrm{ks}$. The spectra were fitted with a Gaussian function with baseline correction. The $\mathrm{Si}-\mathrm{C}$ peak at $100.6 \mathrm{eV}$ was used as the charge reference.

\section{Results and discussion}


On graphite substrates, $2 \mathrm{H}-\mathrm{SiC}$ films were prepared at a deposition temperature of $1010 \mathrm{~K}$ (Fig.

1(a)). The 3C-SiC film formed at higher deposition temperatures (> $1057 \mathrm{~K})$. On (0001) sapphire substrate, the $2 \mathrm{H}-\mathrm{SiC}$ films were prepared at a deposition temperature of $920 \mathrm{~K}$ (Fig. 1(b)). Film deposition was absent at temperatures less than $910 \mathrm{~K}$, whereas (111)-oriented 3C-SiC films were obtained at deposition temperatures $>960 \mathrm{~K}$. Despite the overlapping of diffraction peaks of $\mathrm{SiC}$ polytypes, the existence of $2 \mathrm{H}-\mathrm{SiC} 0112$ diffraction $\left(2 \theta=49.7^{\circ}\right)$ and the lack of $6 \mathrm{H}-\mathrm{SiC} 0114,0115$ and 0117 diffractions $\left(2 \theta=41.5^{\circ}, 45.3^{\circ}\right.$, and $54.7^{\circ}$, respectively) imply the formation of $2 \mathrm{H}-\mathrm{SiC}$.

X-ray pole figures of sapphire 0112 and $2 \mathrm{H}-\mathrm{SiC} 1011$ diffractions of the $2 \mathrm{H}-\mathrm{SiC}$ film showed threefold patterns at an elevated angle ( $\alpha$ ) of $57^{\circ}$ and $40^{\circ}$ (Fig. 2), which corresponded to the interior angle between the (0112) and (0001) sapphire planes, and the (1011) and (2110) 2H-SiC planes, respectively. The X-ray pole figure suggested that the film comprised (2 110$)$-oriented, namely $a$-axis-oriented, $2 \mathrm{H}-\mathrm{SiC}$ grains with an in-plane orientation relationship of [1000] $2 \mathrm{H}-\mathrm{SiC} / /$ [0001] sapphire and [0001] 2H-SiC // [1000] sapphire (Fig. 2(b)).

The 2H-SiC film showed a columnar structure on the (0001) sapphire substrate and the deposition rate of the film was $182 \mu \mathrm{m} \mathrm{h}^{-1}$ (Fig. 3(a)). The surface microstructure of the $2 \mathrm{H}-\mathrm{SiC}$ film was characterized by fine grains with a star flake-like structure (inset, Fig. 3(a)). A bright-field TEM image showed that an equiaxed grain structure was formed on the substrate, and columnar grains developed at later stages of deposition (Fig. 3(b)). In CVD, rapid deposition often results in the preferred growth of 
columnar grains, which subsequently develop into equiaxed grain structures on the substrate [21]. An

SAED pattern taken from the equiaxed grain structure showed a Debye-Scherrer ring (Fig. 3(c)). The ring pattern and corresponding intensity profile (inset, Fig. 3(c)) were indexed as $2 \mathrm{H}-\mathrm{SiC}$. The existence of 2H-SiC 0112 diffraction $\left(d^{-1}=0.55 \mathrm{~nm}^{-1}\right)$ supports the formation of $2 \mathrm{H}-\mathrm{SiC}$ structure, as well as the XRD results. The SAED pattern of the columnar grain belonged to the [1121] zone axis, confirming an $a$-axis-oriented growth of the $2 \mathrm{H}-\mathrm{SiC}$ columnar grains (inset, Fig. 3(b)). A high-resolution TEM image of the columnar grain taken along the [0001] zone axis showed a hexagonal lattice of the (0001) $2 \mathrm{H}-\mathrm{SiC}$ plane (Fig. 3(d)). No stacking faults were observed in the $2 \mathrm{H}-\mathrm{SiC}$ columnar grains.

The CVD synthesis of $2 \mathrm{H}-\mathrm{SiC}$ whiskers on graphite susceptor has been reported with a narrow synthesis temperature window $(30-100 \mathrm{~K})$ at 1573-1773 K [5-9]. Several studies claim that 2H-SiC whiskers grow via the vapor-liquid-solid (VLS) mechanism similar to $\mathrm{Si}$ whiskers because of the presence of spherical terminations and joints [8,9]. Later studies have reported that spherical precipitation prevents the whisker growth, rather than associating with VLS growth [2]. TEM analysis in the present study shows no evidence for VLS growth.

Figure 4 shows the $\mathrm{C} 1 s$, Si $2 p$, and N $1 s$ XPS spectra for the $2 \mathrm{H}-\mathrm{SiC}$ films prepared on the (0001) sapphire substrate. Each XPS spectrum was deconvoluted into two Gaussian peaks, namely, peaks at 283.4 and $284.5 \mathrm{eV}$ in the $\mathrm{C} 1 s$ spectrum (Fig. 4(a)), peaks at 100.6 and $101.7 \mathrm{eV}$ in the $\mathrm{Si} 2 p$ spectrum (Fig. 4(b)), and peaks at 397.6 and $398.7 \mathrm{eV}$ in the N $1 s$ spectrum (Fig. 4(c)). The peak assigned to O-Si 
The peaks at 100.6 and $283.4 \mathrm{eV}$ corresponded to the bonding states of $\mathrm{Si}-\mathrm{C}_{4}(100.6 \mathrm{eV}$ [22]) and $\mathrm{C}-\mathrm{Si}(283.4 \mathrm{eV}$ [22]) in $\mathrm{SiC}$, respectively. The peak at $284.5 \mathrm{eV}$ was associated with the $\mathrm{C}-\mathrm{C}$ bonding between C-rich $\mathrm{SiC}$ [23] and a free carbon. The peaks at 101.7 and $397.6 \mathrm{eV}$ were consistent with the $\mathrm{Si}-\mathrm{N}_{4}(101.7-101.9 \mathrm{eV}[24,25])$ and $\mathrm{N}-\mathrm{Si}(397.8 \mathrm{eV}[24,25])$ bonding states in $\mathrm{Si}_{3} \mathrm{~N}_{4}$, respectively. A small shoulder at $398.7 \mathrm{eV}$ in the $\mathrm{N} 1 s$ spectrum might be related to the incorporation of an $\mathrm{NH}$ species $(\mathrm{Si}-\mathrm{NH}-\mathrm{Si})$ or an $\mathrm{NH}_{2}$ fragment bonded to $\mathrm{Si}\left(\mathrm{Si}-\mathrm{N}=(\mathrm{H})_{2}\right)$ [26] rather than a $\mathrm{N}$ atom bonded to $\mathrm{C}$, owing to the absence of a $\mathrm{C}-\mathrm{N}$ peak at $286.5 \mathrm{eV}$ [27] in the $\mathrm{C} 1 s$ spectrum.

The $\mathrm{Si} 2 p$ peak was fitted with $\mathrm{Si}-\mathrm{C}_{4}$ and $\mathrm{Si}-\mathrm{N}_{4}$ peaks that have narrow full-width and half-maxima $(1.6 \mathrm{eV}$ and $1.3 \mathrm{eV})$ that are comparable to the reference values $(1.8 \mathrm{eV}[22]$ and $2.1 \mathrm{eV}$ [25]). Although $\mathrm{C}$ atoms in $\mathrm{SiC}$ might be substituted by $\mathrm{N}$, no intermediate bonding states of $\mathrm{Si}-\mathrm{C}-\mathrm{N}$ were identified. $\mathrm{N}$ concentration in $\mathrm{SiC}$ is commonly on the order of $10^{15}-10^{20} \mathrm{~cm}^{-3}$, which is much lower than the detection limit of XPS [22]. On the other hand, a N concentration close to the solubility limit $\left(10^{19}-10^{20} \mathrm{~cm}^{-3}\right)$ resulted in the formation of stacking faults and a phase transformation from $4 \mathrm{H}$ to $3 \mathrm{C}$ [30-32]. First principles calculations also implied that substitution of $\mathrm{C}$ with $\mathrm{N}$ atoms destabilized $6 \mathrm{H}-$, 4H-, and especially $2 \mathrm{H}-\mathrm{SiC}$ [33]. Therefore, $\mathrm{N}$ concentration in $\mathrm{SiC}$ might be less than the solubility limit at least. Since the XRD and TEM-SAED patterns revealed no evidence for crystalline $\mathrm{Si}_{3} \mathrm{~N}_{4}$, most of the nitrogen likely coexisted in the $2 \mathrm{H}-\mathrm{SiC}$ films as a trace amount $\left(3 \mathrm{~mol} \%\right.$ ) of amorphous $\mathrm{Si}_{3} \mathrm{~N}_{4}$ rather than 
N-substitution in SiC.

According to the thermal stability diagrams of the SiC polytypes summarized by Knippenberg

[12] and Inomata et al. [34], 2H-SiC may be stable at less than $1673 \mathrm{~K}$ [12]. However, 2H-SiC were only obtained as whiskers, which grew under a large temperature gradient. 3C-SiC films have mostly been obtained by CVD over a wide temperature range (1373-2673 K). This might be attributed to the symmetric tetrahedral and octahedral shapes of $3 \mathrm{C}-\mathrm{SiC}$ nuclei having lower surface energies than the hexagonal prismatic nuclei of $4 \mathrm{H}-$ and $6 \mathrm{H}-\mathrm{SiC}$ polymorphs while in the gas phase $[34,35]$ and in particular a highly supersaturated Si-excess atmosphere [34]. Conversely, first principles calculations suggested that a Si vacancy may stabilize $2 \mathrm{H}-\mathrm{SiC}$ [33]. Therefore, a Si-poor environment and a relatively large temperature gradient established by laser irradiation would favor the formation of $2 \mathrm{H}-\mathrm{SiC}$ films. It is noteworthy that while $2 \mathrm{H}-\mathrm{SiC}$ films have never been prepared by conventional CVD, we report the possibility of preparing $2 \mathrm{H}-\mathrm{SiC}$ films by laser CVD using 3DMAS precursor and $\mathrm{CH}_{4}$ atmosphere.

\section{Conclusions}

By using laser CVD with 3DMAS precursor, films of $2 \mathrm{H}-\mathrm{SiC}$ were prepared on graphite and (0001) sapphire substrates at deposition temperatures of $1010 \mathrm{~K}$ and $920 \mathrm{~K}$, respectively. The typical deposition rate was $182 \mu \mathrm{m} \mathrm{h}^{-1}$. The $2 \mathrm{H}$-SiC films prepared on (0001) sapphire substrates were composed of $a$-axis-oriented $2 \mathrm{H}-\mathrm{SiC}$ columnar grains. The in-plane orientation relationship of the $a$-axis-oriented 
2H-SiC grains was [1000] 2H-SiC // [0001] sapphire and [0001] 2H-SiC // [1000] sapphire. A trace amount of amorphous $\mathrm{Si}_{3} \mathrm{~N}_{4}$ might coexist in the $2 \mathrm{H}-\mathrm{SiC}$ films.

\section{Acknowledgements}

This research was supported in part by a Grant-in-Aid for Young Scientists (A) (No. 25709069)

from the Japan Society for the Promotion of Science (JSPS), and in part by Council for Science,

Technology and Innovation (CSTI), Cross-ministerial Strategic Innovation Promotion Program (SIP),

"Structural Materials for Innovation" (Funding agency: JST). XPS measurement was supported by the cooperative program (No. 15G0410) of the CRDAM-IMR, Tohoku University, Japan.

\section{References}

[1] Maboudian R, Carraro C, Senesky DG, Roper CS. Advances in silicon carbide science and technology at the micro- and nanoscales. J. Vac. Sci. Technol. A 2013;31(5):050805.

[2] Patrick L, Hamilton DR, Choyke WJ. Growth, Luminescence, Selection Rules, and Lattice Sums of SiC with Wurtzite Structure. Phys. Rev. 1966;143(2):526-36.

[3] Okumura H. Present Status and Future Prospect of Widegap Semiconductor High-Power Devices. Jpn. J. Appl. Phys. 2006;45(10R):7565. 
[4] Nilsson H-E, Hjelm M. Monte Carlo simulation of electron transport in $2 \mathrm{H}-\mathrm{SiC}$ using a three valley analytical conduction band model. J. Appl. Phys. 1999;86(11):6230-3.

[5] Merz KM, Adamsky RF. Synthesis of the wurtzite form of silicon carbide. J. Am. Chem. Soc. 1959;81(1):250-1.

[6] Powell JA. Crystal Growth of 2H Silicon Carbide. J. Appl. Phys. 1969;40(11):4660-2.

[7] Setaka N, Eshri M. Evidence for $2 \mathrm{H}-\mathrm{SiC}$ Whisker Growth by a Screw Dislocation Process. $J$. Am. Ceram. Soc. 1969;52(7):400.

[8] Berman I, Ryan CE. The growth of silicon carbide needles by the vapor-liquid-solid method. $J$. Cryst. Growth 1971;9:314-8.

[9] Addamiano A. Preparation and properties of $2 \mathrm{H}$ SiC crystals. J. Cryst. Growth 1982;58(3):617-22.

[10] Schlichting J. Chemical Vapor Deposition of Silicon Carbide. Powder Metall. Int. 1980;12(3):141-7.

[11] Pedersen H, Leone S, Kordina O, Henry A, Nishizawa S, Koshka Y, Janzén E. Chloride-Based CVD Growth of Silicon Carbide for Electronic Applications. Chem. Rev. 2012;112(4):2434-53. 
[12] Knippenberg WF. Growth phenomena in silicon carbide. Philips Res. Rep. $1963 ; 18(3): 161-274$

[13] Hashimoto R, Ito A, Goto T. Effect of deposition atmosphere on the phase composition and microstructure of silicon carbide films prepared by laser chemical vapour deposition. Ceram. Int. 2015;41(5, Part B):6898-904.

[14] Fujie K, Ito A, Tu R, Goto T. Laser chemical vapor deposition of SiC films with $\mathrm{CO}_{2}$ laser. $J$. Alloys Compd. 2010;502(1):238-42.

[15] Zhang S, Xu Q, Tu R, Goto T, Zhang L. High-Speed Preparation of <111>- and $<110>-$ Oriented $\beta$-SiC Films by Laser Chemical Vapor Deposition. J. Am. Ceram. Soc. 2014;97(3):952-8.

[16] Burton BB, Kang SW, Rhee SW, George SM. $\mathrm{SiO}_{2}$ Atomic Layer Deposition Using Tris(dimethylamino)silane and Hydrogen Peroxide Studied by in Situ Transmission FTIR Spectroscopy. J. Phys. Chem. C 2009;113(19):8249-57.

[17] Wrobel AM, Blaszczyk-Lezak I, Uznanski P, Glebocki B. Silicon Carbonitride (SiCN) Films by Remote Hydrogen Microwave Plasma CVD from Tris(dimethylamino)silane as Novel Single-Source Precursor. Chem. Vap. Depos. 2010;16(7-9):211-5. 
[18] Ito A, Kadokura H, Kimura T, Goto T. Texture and orientation characteristics of $\alpha-\mathrm{Al}_{2} \mathrm{O}_{3}$ films

prepared by laser chemical vapor deposition using Nd:YAG laser. J. Alloys Compd. 2010;489(2):469-74.

[19] Zhang L, Holt CMB, Luber EJ, Olsen BC, Wang H, Danaie M, Cui X, Tan X, W. Lui V, Kalisvaart WP, Mitlin D. High Rate Electrochemical Capacitors from Three-Dimensional Arrays of Vanadium Nitride Functionalized Carbon Nanotubes. J. Phys. Chem. C 2011;115(49):24381-93.

[20] Momma K, Izumi F. VESTA 3 for three-dimensional visualization of crystal, volumetric and morphology data. J. Appl. Crystallogr. 2011;44(6):1272-6.

[21] Bryant WA. The fundamentals of chemical vapour deposition. J. Mater. Sci. 1977;12(7):1285-306.

[22] Bozack MJ. Single Crystal 6H-SiC(0001) by XPS. Surf. Sci. Spectra 1994;3(1):82-5.

[23] Simon L, Bischoff JL, Kubler L. X-ray photoelectron characterization of 6H-SiC (0001). Phys. Rev. $B$ 1999;60(16):11653-60.

[24] Benkherourou O, Sahnoune S, Djabi M, Deville J-P. Analysis of photoemission lines in silicon nitrided layers formed by low-energy nitrogen ion implantation in silicon. Vacuum 
1999;53(3-4):427-33.

[25] Chourasia AR, Chopra DR. A Study of $\mathrm{Si}_{3} \mathrm{~N}_{4}$ by XPS. Surf. Sci. Spectra 1993;2(2):117-22.

[26] Bischoff JL, Lutz F, Bolmont D, Kubler L. Use of multilayer techniques for XPS identification of various nitrogen environments in the $\mathrm{Si} / \mathrm{NH}_{3}$ system. Surf. Sci. 1991;251-252:170-4.

[27] Yamamoto K, Koga Y, Fujiwara S. Binding Energies of Amorphous CN and SiCN Films on X-Ray Photoelectron Spectroscopy. Jpn. J. Appl. Phys. 2001;40(2A):L123.

[28] Augustine G, Hobgood M, Balakrishna V, Dunne G, Hopkins RH. Physical Vapor Transport Growth and Properties of $\mathrm{SiC}$ Monocrystals of $4 \mathrm{H}$ Polytype. Phys. Status Solidi B 1997;202(1):137-48.

[29] Bockstedte M, Mattausch A, Pankratov O. Solubility of nitrogen and phosphorus in 4H-SiC: A theoretical study. Appl. Phys. Lett. 2004;85(1):58-60.

[30] Okojie RS, Xhang M, Pirouz P, Tumakha S, Jessen G, Brillson LJ. Observation of 4H-SiC to 3C-SiC polytypic transformation during oxidation. Appl. Phys. Lett. 2001;79(19):3056-8.

[31] Liu JQ, Chung HJ, Kuhr T, Li Q, Skowronski M. Structural instability of 4H-SiC polytype induced by n-type doping. Appl. Phys. Lett. 2002;80(12):2111-3. 
[32] Pirouz P, Zhang M, Hobgood HM, Lancin M, Douin J, Pichaud B. Nitrogen doping and multiplicity of stacking faults in SiC. Philos. Mag. 2006;86(29-31):4685-697.

[33] Ito T, Akiyama T, Nakamura K. Systematic theoretical investigations for the polytypism in SiC. Phys. Status Solidi C 2013;10(5):857-60.

[34] Fissel A. Thermodynamic considerations of the epitaxial growth of SiC polytypes. J. Cryst. Growth 2000;212(3-4):438-50.

[35] Inomata $\mathrm{Y}$, Matsumoto $\mathrm{S}$. On the Formation of $\beta-\mathrm{SiC}$ in the Initial Growth Stage. J. Ceram. Assoc. Jpn. 1971;79(905):40-6. 


\section{Figure captions}

Figure 1 XRD patterns of the $2 \mathrm{H}-\mathrm{SiC}$ films prepared (a) on graphite substrates at $1010 \mathrm{~K}$, and (b) on (0001) sapphire at $920 \mathrm{~K}$. Inset patters were measured at a slow scan condition. Reference lines: $2 \mathrm{H}-\mathrm{SiC}$ (ICSD No. 86253), 3C-SiC (No. 24271), and 6H-SiC (ICSD No. 156190).

Figure 2 (a) X-ray pole figures of (0112) sapphire and (1011) 2H-SiC planes of the $2 \mathrm{H}-\mathrm{SiC}$ film. (b) Schematic of the in-plane orientation relationship between (2110) 2H-SiC and (0001) sapphire planes.

Figure 3 (a) Cross-sectional and (inset in a) surface SEM images of the 2H-SiC film prepared on (0001) sapphire substrate. (b) Bright-field TEM image and (inset in b) SAED pattern taken from columnar grain along the [1121] zone axis. (c) SAED pattern taken from equiaxed grain structure and reference line of 2H-SiC structure. Inset in (c) shows the intensity profile of the SAED pattern. (d) High-resolution TEM images of the $2 \mathrm{H}-\mathrm{SiC}$ columnar grain taken along the [0001] zone axis and corresponding atomic arrangement.

Figure 4 (a) C $1 s$, (b) Si 2p, and (c) N $1 s$ XPS spectra for the 2H-SiC film prepared on a (0001) sapphire substrate. The inset in c shows the O $1 s$ XPS spectrum. 
Fig.01 XRD patterns of $2 \mathrm{H}-\mathrm{SiC}$ films

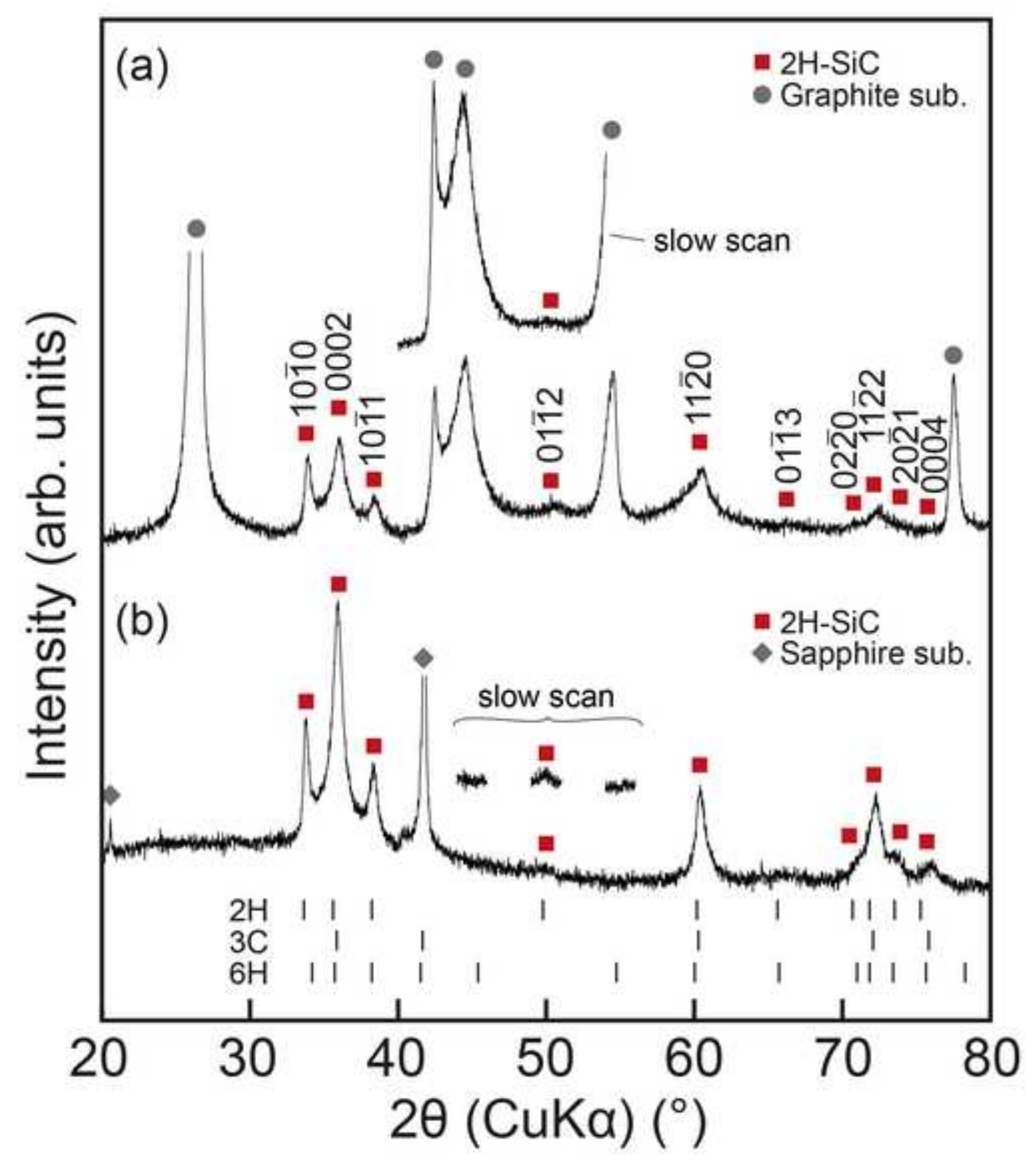




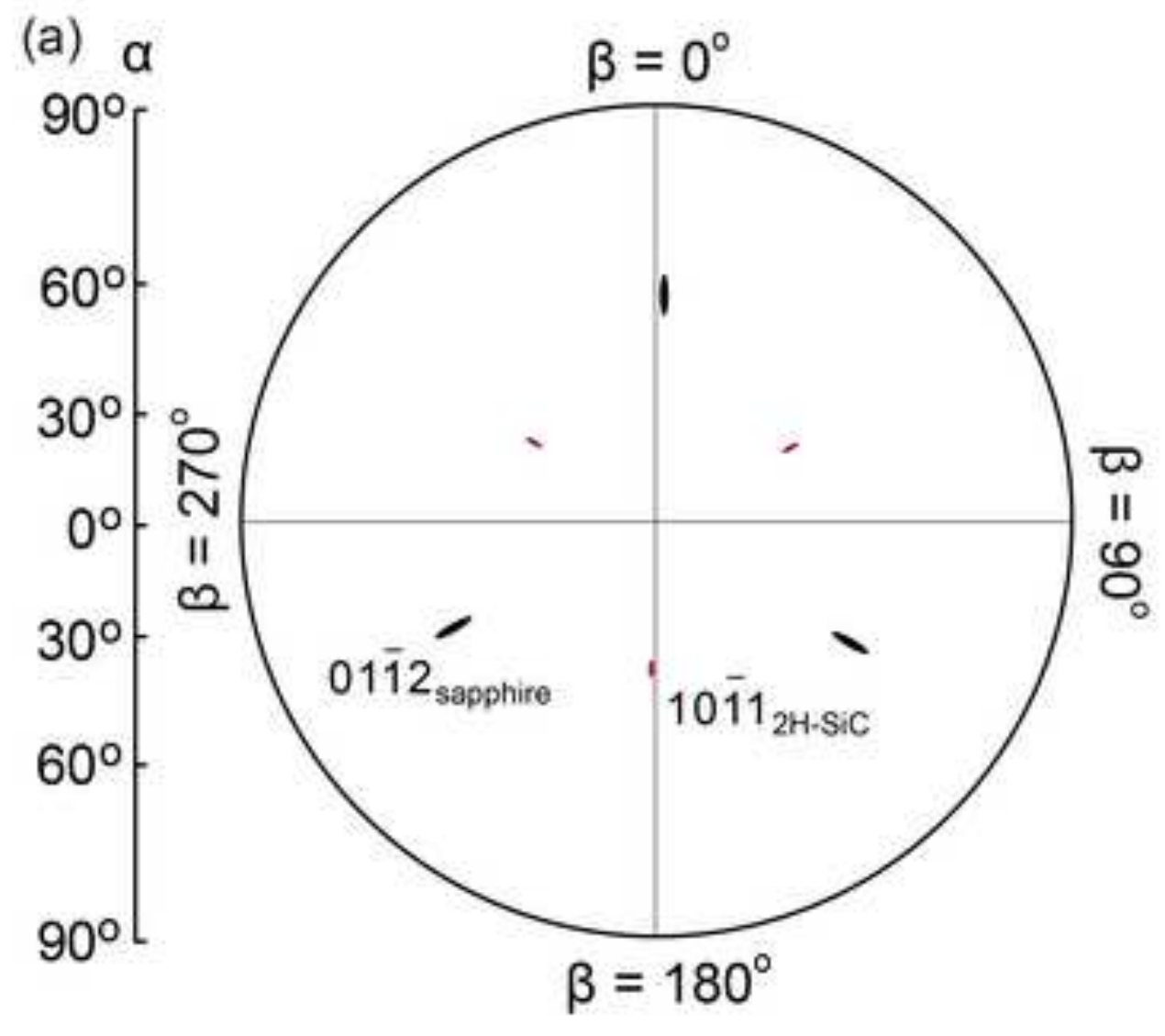

(b)

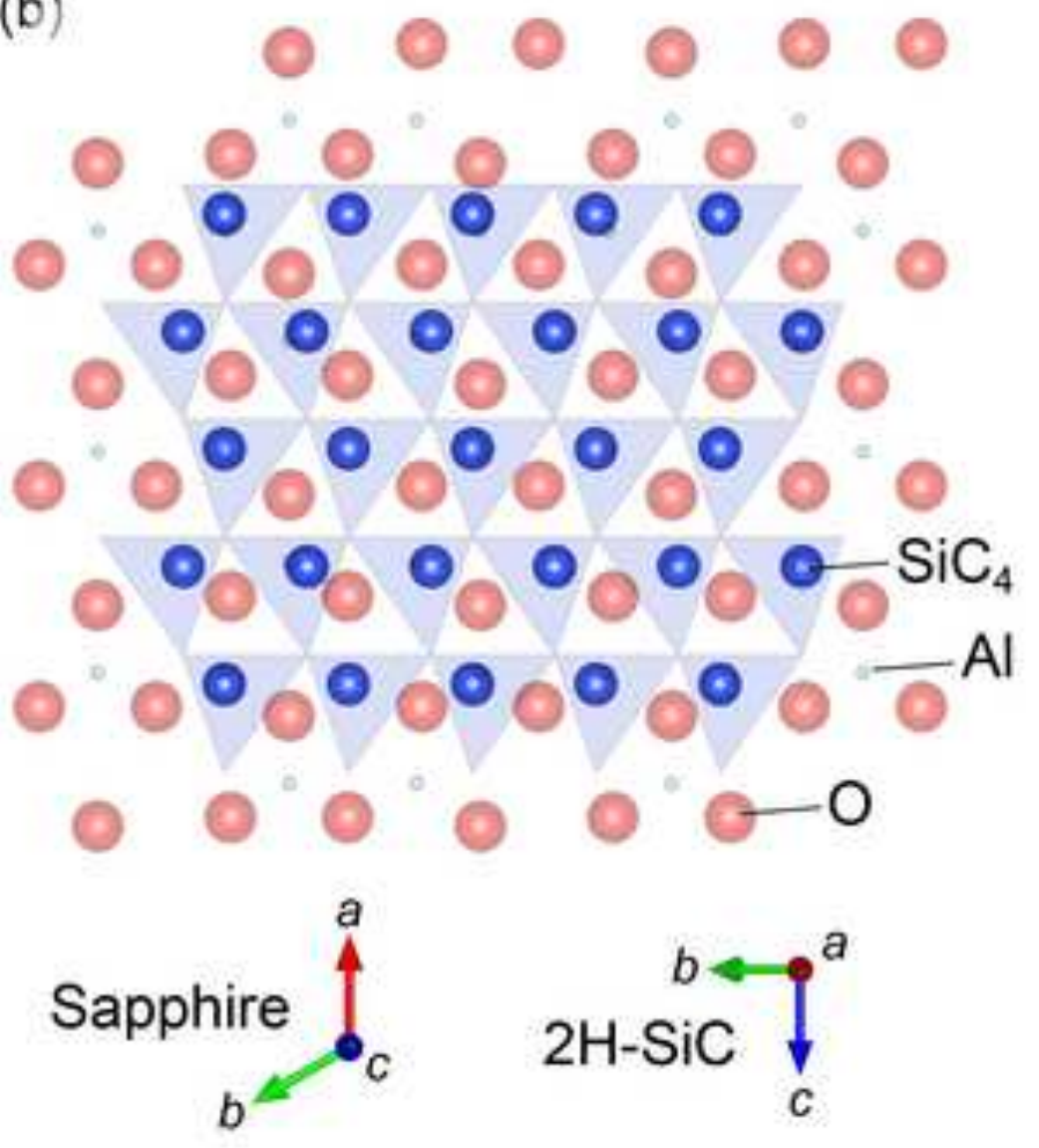


(a)

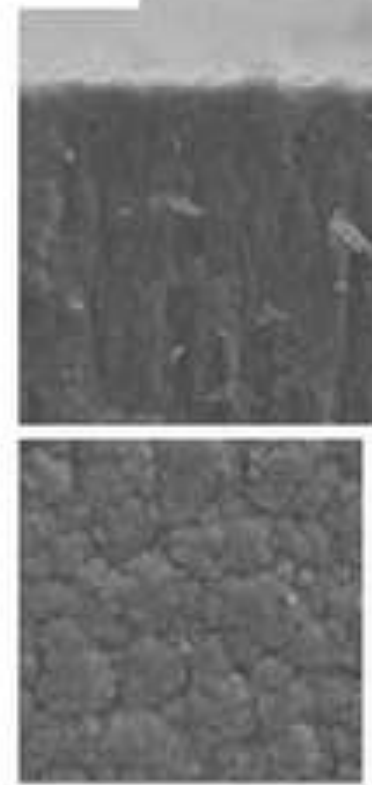

(c)

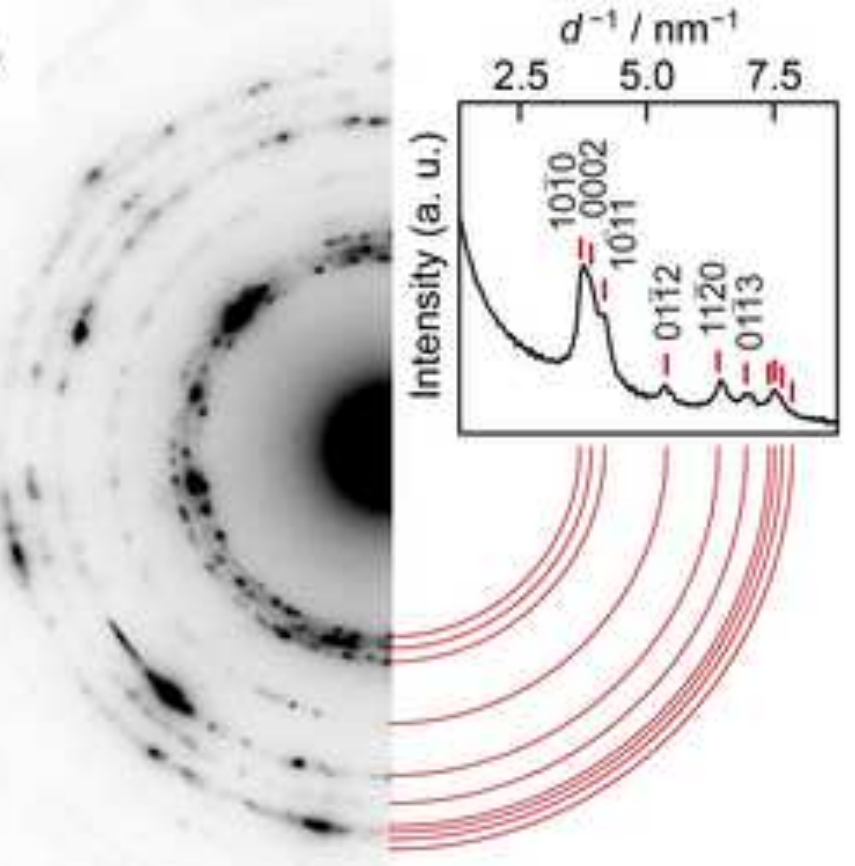

(b)

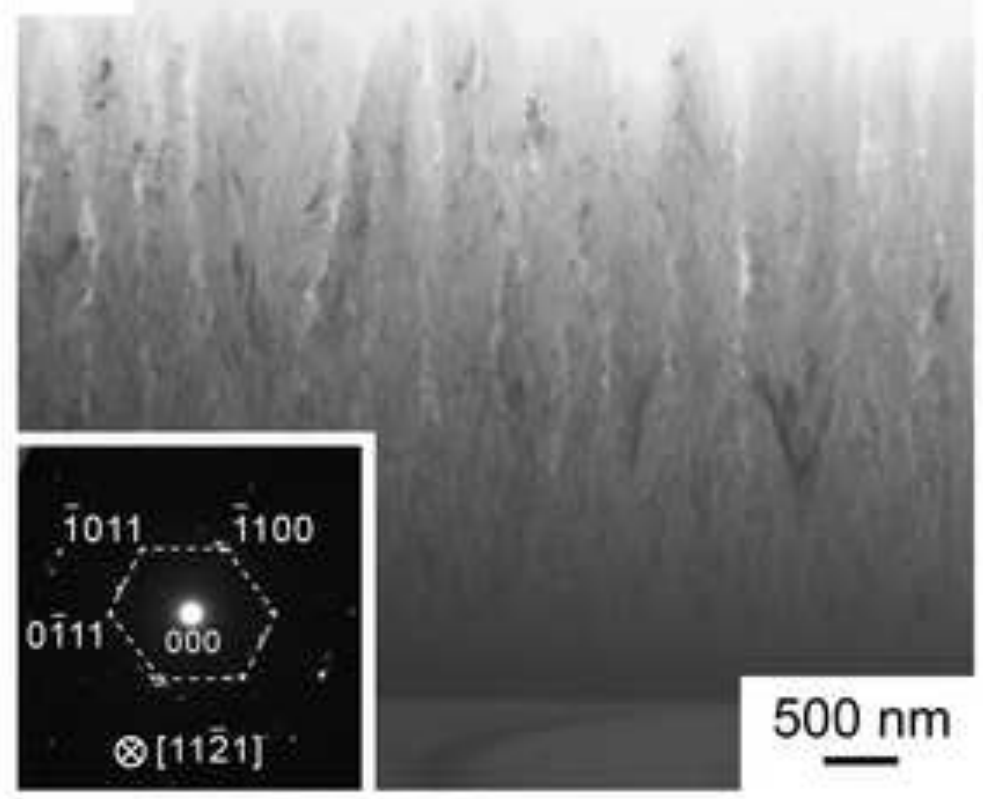

(d)

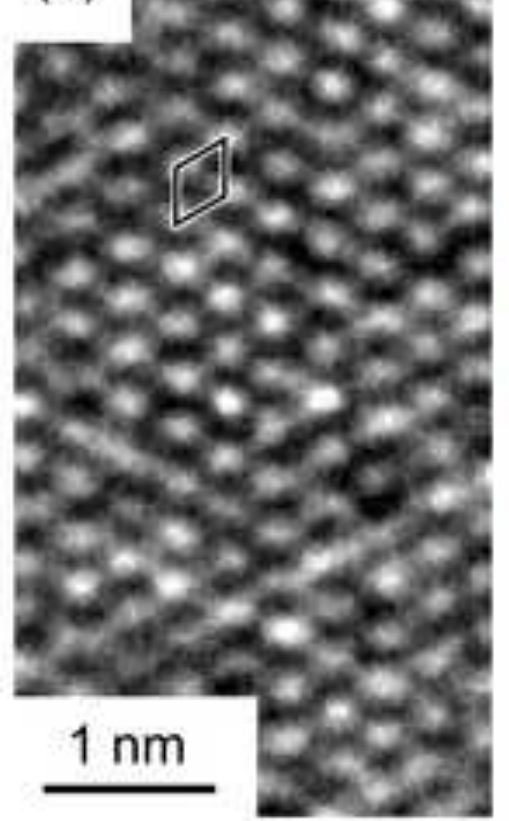

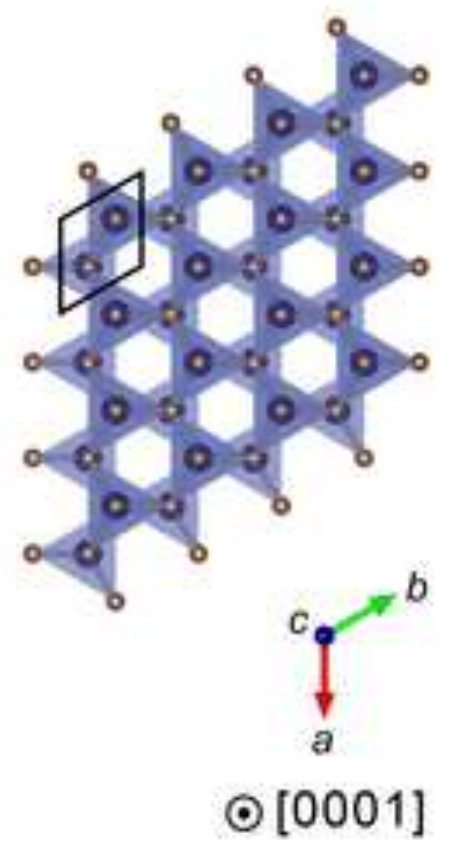



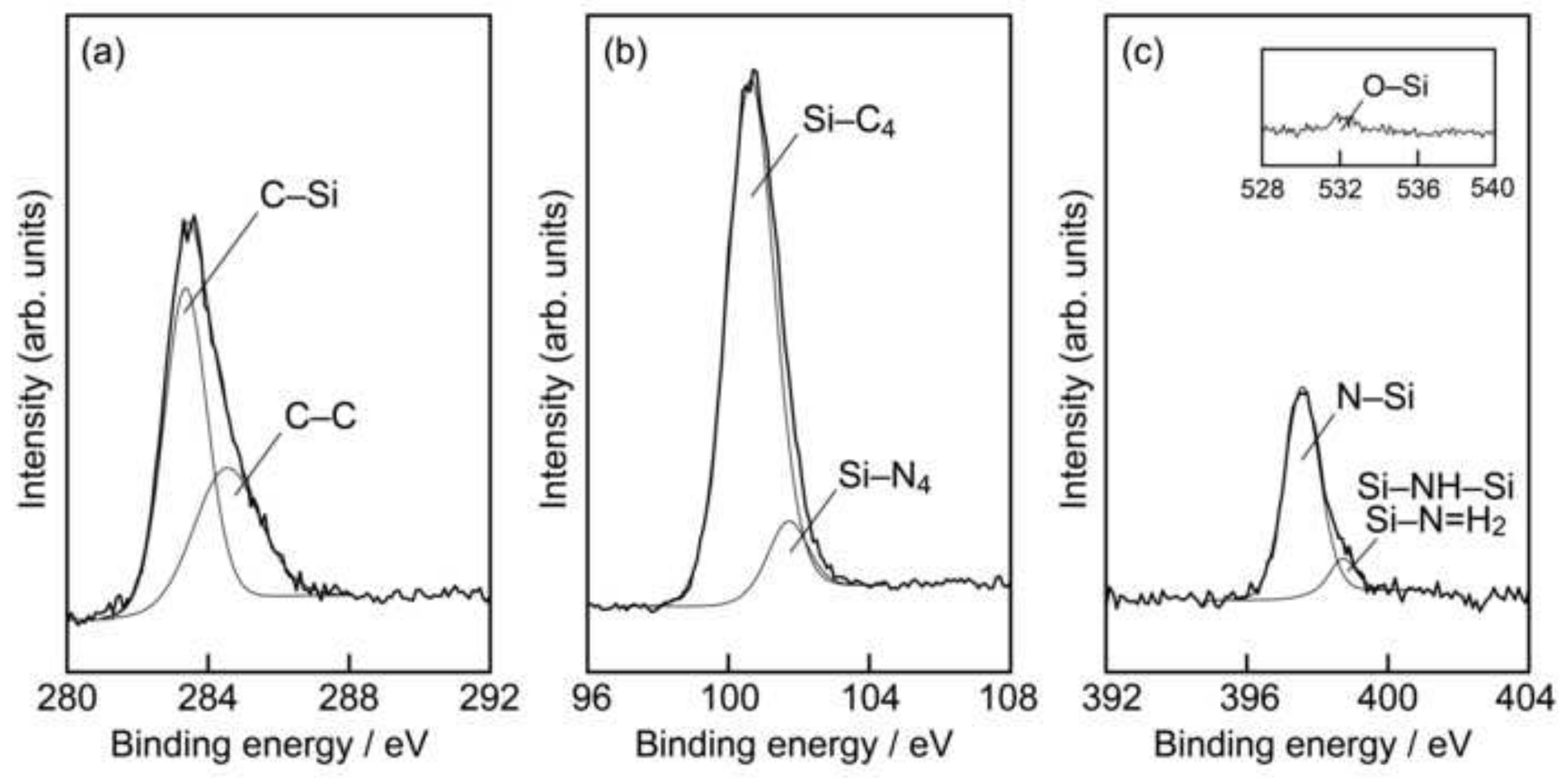


\section{Figure captions}

Figure 1 XRD patterns of the $2 \mathrm{H}-\mathrm{SiC}$ films prepared (a) on graphite substrates at $1010 \mathrm{~K}$, and (b) on (0001) sapphire at $920 \mathrm{~K}$. Inset patters were measured at a slow scan condition. Reference lines: $2 \mathrm{H}-\mathrm{SiC}$ (ICSD No. 86253), 3C-SiC (No. 24271), and 6H-SiC (ICSD No. 156190).

Figure 2 (a) X-ray pole figures of (0112) sapphire and (1011) 2H-SiC planes of the 2H-SiC film. (b) Schematic of the in-plane orientation relationship between (2110) 2H-SiC and (0001) sapphire planes.

Figure 3 (a) Cross-sectional and (inset in a) surface SEM images of the 2H-SiC film prepared on (0001) sapphire substrate. (b) Bright-field TEM image and (inset in b) SAED pattern taken from columnar grain along the [1121] zone axis. (c) SAED pattern taken from equiaxed grain structure and reference line of 2H-SiC structure. Inset in (c) shows the intensity profile of the SAED pattern. (d) High-resolution TEM images of the $2 \mathrm{H}-\mathrm{SiC}$ columnar grain taken along the [0001] zone axis and corresponding atomic arrangement.

Figure 4 (a) C $1 s$, (b) Si 2p, and (c) N $1 s$ XPS spectra for the 2H-SiC film prepared on a (0001) sapphire substrate. The inset in c shows the O $1 s$ XPS spectrum. 